Burcu Zeydan, MD

Ugur Uygunoglu, MD

Sabahattin Saip, MD

Onat N. Demirci, MD

Emire Seyahi, MD

Serdal Ugurlu, MD

Vedat Hamuryudan, MD

Aksel Siva, MD

Orhun H. Kantarci, MD

Correspondence to

Dr. Kantarci:

kantarci.orhun@mayo.edu

\title{
Infliximab is a plausible alternative for neurologic complications of Behçet disease
}

OPEN

\section{ABSTRACT}

Objective: We evaluated the effectiveness of infliximab in patients with neuro-Behçet syndrome for whom other immunosuppressive medications had failed.

Methods: Patients whose common immunosuppressive medications fail in recurrent neuro-Behçet syndrome need an alternative. We report our experience with the tumor necrosis factor $\alpha$ blocker infliximab for long-term treatment of neuro-Behçet syndrome. We recruited patients within a multidisciplinary referral practice of Behçet disease and prospectively followed everyone with a neurologic symptom(s). Patients ( $n=16$ ) with $\geq 2$ neurologic bouts (excluding purely progressive disease) while on another immunosuppressive treatment were switched to and successfully sustained on infliximab $(5 \mathrm{mg} / \mathrm{kg}$ in weeks 0,2 , and 6 , then once every 8 weeks; minimum follow-up duration $\geq 12$ months). Infliximab was stopped within 2 months after initiation in one patient because of pulmonary and CNS tuberculosis.

Results: Patients had stepwise worsening due to relapses in the Expanded Disability Status Scale modified for neuro-Behçet syndrome before switching to infliximab (median score of 5.0, range 2.0-7.0; median neuro-Behçet syndrome duration 29.1 months, range 5.0-180.7). Median duration of preinfliximab immunosuppressive medication use was 20.0 months (range 3.0-180.7). In all 15 patients, during infliximab treatment (median score 4.0, range 2.0-7.0; median duration 39.0 months, range 16.0-104.9 months), neurologic relapses were completely aborted and there was no further disability accumulation.

Conclusion: We observed a significant beneficial effect of infliximab in neuro-Behçet syndrome.

Classification of evidence: This study provides Class IV evidence that for patients with neuroBehçet syndrome whose other immunosuppressive medications failed, infliximab prevents further relapses and stabilizes disability. Neurol Neuroimmunol Neuroinflamm 2016;3:e258; doi: 10.1212/ NXI.0000000000000258

\section{GLOSSARY}

BD = Behçet disease; EDSS-NBS = Expanded Disability Status Scale modified for neuro-Behçet syndrome; NBS = neuroBehçet syndrome; TNF- $\alpha=$ tumor necrosis factor $\alpha$; VST $=$ venous sinus thrombosis

Behçet disease (BD) is an idiopathic, chronic relapsing, multisystem, vascular-inflammatory disease. ${ }^{1}$ The diagnosis requires recurrent oral aphthous ulcerations and 2 of the following: (1) genital ulcerations, (2) skin lesions, (3) eye lesions, and (4) positive pathergy test. ${ }^{2}$

Neurologic involvement or neuro-Behçet syndrome (NBS) occurs in about $5 \%$ of patients with BD. ${ }^{3}$ Approximately $75 \%$ of NBS cases present with CNS involvement termed parenchymal neuro-Behçet syndrome, affecting the telencephalic-diencephalic junction, brainstem, and the spinal cord. ${ }^{3,4}$ Cerebral venous sinus thrombosis (VST) occurs in up to $20 \%$ of the patients with neurologic involvement. ${ }^{3,4}$ VST and rare intra-extracranial aneurysms is also known as "nonparenchymal NBS." 4,5

From the Departments of Neurology (B.Z., U.U., S.S., O.N.D., A.S.) and Rheumatology (E.S., S.U., V.H.), Istanbul University, Cerrahpasa School of Medicine, Istanbul, Turkey; and Department of Neurology (B.Z., O.H.K.), Mayo Clinic College of Medicine, Rochester, MN.

Funding information and disclosures are provided at the end of the article. Go to Neurology.org/nn for full disclosure forms. The Article Processing Charge was paid by the authors.

This is an open access article distributed under the terms of the Creative Commons Attribution-NonCommercial-NoDerivatives License 4.0 (CC BY-NC-ND), which permits downloading and sharing the work provided it is properly cited. The work cannot be changed in any way or used commercially. 
After 3 years from NBS onset, 1 in 3 patients has no further recurrences, 1 in 3 has recurrent relapses, and 1 in 3 has progressively worsening disease. ${ }^{3}$ Similar to multiple sclerosis, disability can accumulate either due to partially recovered relapses or due to the progressive disease course. ${ }^{3}$

There are no randomized controlled trials in NBS. All current treatments are labeled as nonevidence-based by the European League Against Rheumatism Committee. ${ }^{6,7}$ The International Neuro-Behçet Syndrome Advisory Group recommended azathioprine as a first-line treatment for NBS (alternatives included mycophenolate mofetil, methotrexate, and cyclophosphamide). ${ }^{5}$ Tumor necrosis factor $\alpha$ (TNF- $\alpha$ ) blockers or interferon $\alpha$ were recommended as anecdotal second-line options for first-line therapy failure, intolerance, or an aggressive course. 5 The experience with TNF- $\alpha$ blockers remains limited to case reports in NBS. ${ }^{8-26}$ TNF- $\alpha$ blockers are used successfully in many other autoimmune diseases such as inflammatory bowel disease $\mathrm{e}^{27,28}$ and in systemic complications of BD. ${ }^{29,30} \mathrm{We}$ report a relatively large case series of infliximab in NBS to prevent relapses and stabilize disability.

METHODS Research question. Is there an alternative or adjunct medication when other immunosuppressive medications fail for patients with NBS? This study provides Class IV evidence that for patients with NBS whose other immunosuppressive medications failed, infliximab prevents further relapses and stabilizes disability.

Study population. All patients were originally seen in Istanbul University Cerrahpasa School of Medicine "Behçet's Clinic" (originated by Dr. Hulûsi Behçet). This is a multidisciplinary subspecialty clinical practice of rheumatology, dermatology, ophthalmology and neurology. All patients with NBS have MRI studies with gadolinium during bouts of neurologic complications to document that the neurologic syndrome is due to NBS. Relapses are treated with daily $1 \mathrm{~g}$ IV methylprednisolone infusion for 7 to 10 consecutive days. MRI studies are generally repeated following treatment for relapses to confirm clinicalradiologic concordance of improvement in lesions. However, unlike multiple sclerosis, in our experience, asymptomatic CNS parenchymal lesions do not happen in NBS. Therefore, in this open-label, real-life clinical use of infliximab, there were no set time intervals for routine imaging studies.

Standard protocol approvals, registrations, and patient consents. We received approval for the study from an institutional ethical standards committee. While available as an adjunct based on individual case reports, infliximab can have potential side effects. Therefore, a written informed consent was obtained from all patients (or guardians of patients) participating in the study at the initiation of treatment.
Study criteria. Despite being an open-label, real-life clinical experience report, given the homogeneity and multidisciplinary tradition of our clinic, stringent criteria are utilized when switching a patient from traditional immunosuppressive agents to infliximab. These criteria are listed in table 1 .

Of the 155 patients, there were 28 who had fulfilled the enrollment criteria, but 12 of them were not treated with infliximab (figure 1). Reasons for not initiating treatment were inconvenient follow-up and compliance concerns, lack of insurance coverage for biologics, and recurrent but limited VST without any parenchymal NBS $(n=4)$. For the final analyses, there were 16 patients who were treated with infliximab between 2006 and 2014 in an open-label manner (figure 1). All patients were switched to infliximab because of continued neurologic relapses under immunosuppressive treatment. One patient with only recurrent VST was still included in this group because of recurrent widespread systemic venous thrombosis, cardiac thrombosis, as well as pulmonary artery aneurysms despite other immunosuppressant use.

Potential side effects of infliximab, such as rash, headaches, nausea, and infections, were monitored for and treated appropriately. In one patient, infliximab was discontinued at month 2 because of evidence of active pulmonary and CNS tuberculosis. This patient was excluded from the final analyses because of short duration of treatment.

After NBS onset, including both the pre- and postinfliximab periods, a total of 123 clinical assessments and 45 brain MRIs were completed and analyzed in the final 15 patients included in the study.

Intervention and outcome assessment. Following steroid treatment, $5 \mathrm{mg} / \mathrm{kg}$ infliximab was administered at weeks 0,2 , and 6 , then once every 8 weeks. Given the devastating nature of relapses in NBS, the primary outcome of the study was absolute cessation of neurologic relapses. The secondary outcome was stabilization of disability accumulation resulting from relapses.

Disability was measured using the Expanded Disability Status Scale modified for NBS (EDSS-NBS) as previously published. ${ }^{3}$ The EDSS was originally devised for multiple sclerosis-associated disability. ${ }^{31}$ All functional systems affected in multiple sclerosis can also be affected in NBS except that the visual functional system involvement is significantly different. Considering that the visual disability is most commonly due to uveitis in $\mathrm{BD}$ (as opposed to optic neuritis in multiple sclerosis), and nonneurologic blindness is more common in $\mathrm{BD}$, the visual functional system score was eliminated from the original scale as previously discussed. ${ }^{3}$

Per the inclusion criteria requirement of recurrent relapses, no patient with otherwise progressively worsening disease course in the absence of relapses was included in the study. Therefore, all EDSS-NBS changes in our study could be accounted for by individual relapses, and the last EDSS-NBS score recorded was assumed unchanged until the next clinical visit.

Data analyses. Demographics of the study population were compared in 3 groups: (1) patients who did not fulfill the enrollment criteria, (2) patients who fulfilled the enrollment criteria but were not treated with infliximab, and (3) patients who fulfilled the enrollment criteria and were treated with infliximab. Sex distribution, median age at $\mathrm{BD}$ and NBS onsets, median time from BD to NBS, syndrome at NBS onset, duration of NBS, and last visit EDSS-NBS scores were compared using either 2-tailed Student $t$ test or $\chi^{2}$ test statistics appropriate to the variable.

Several NBS-related characteristics and specifics of our case series were considered when presenting the data regarding the 


\section{Table $1 \quad$ Study criteria}

Inclusion criteria

Behçet disease diagnosis fulfilling the International Diagnostic Criteria²

Occurrence of neurologic symptoms, not otherwise explained by any other known systemic or neurologic disease or treatment, and in whom objective abnormalities consistent with neuroBehçet syndrome are detected on neurologic examination, and/or with neuroimaging studies (MRI), and/or abnormal CSF examination. ${ }^{3,4}$

Patients who develop $\geq 2$ neurologic bouts while on another immunosuppressive treatment

Completion of $\geq 12$ mo of treatment with infliximab

Exclusion criteria

Active infections

Past or present history of tuberculosis or other opportunistic infections

History of malignancy, documented hypersensitivity and allergic reactions, severe heart failure

final disability outcome. Unlike in other diseases such as multiple sclerosis, the relapses in NBS have a rather poor recovery leading to stepwise disability accumulation in most patients with NBS. ${ }^{3}$

Because of nonstandardized follow-up times of the real-world practice, the results are shown in 2 ways: (1) for a group effect, using the total of 123 clinical assessments for EDSS-NBS, median EDSS-NBS was calculated for each month, comparing the preinfliximab period with the postinfliximab period (figure $2 \mathrm{~A}$ ), censored between the 2 time points of median preinfliximab NBS duration and median infliximab use duration; and (2) EDSSNBS accumulation rate between pre- and postinfliximab periods was calculated for each individual patient (figure 2B).

RESULTS Demographics of the study population. Patients who had $\geq 2$ relapses of NBS while using other immunosuppressive medications, therefore fulfilling the study enrollment criteria, had a longer NBS duration before the initiation of infliximab (median 35.0, range 5.0-292.1) than the total NBS duration in those who did not fulfill the criteria (median 13.0, range 1.0-276.0) ( $p=0.013$ ) (table 2). As discussed in the methods section, there was a trend for patients who fulfilled enrollment criteria but did not receive infliximab to be more likely to have VST at onset (table 2). There were no other demographic differences between criteria positive and negative groups or infliximab positive and negative groups $(p>0.05)$.

Preinfliximab disease course. Immunomodulatory/ immunosuppressive treatments used before infliximab initiation and anytime until the last follow-up for those who did not receive infliximab are shown in table 2 . Of the 15 patients who successfully tolerated infliximab, before the medication switch, 5 patients were previously using a single agent: azathioprine $(\mathrm{n}=2)$, cyclophosphamide $(n=2)$, or interferon $\alpha(n=1)$. Six patients were using a 2-agent combination of azathioprine with cyclophosphamide $(\mathrm{n}=1)$, colchicine $(\mathrm{n}=1)$, or prednisolone $(\mathrm{n}=4)$, while 2 patients were using cyclophosphamide and prednisolone. Two patients were using a 3-agent combination of azathioprine, prednisolone, and cyclophosphamide. For 3 patients, NBS onset was earlier than any long-term treatment initiation, therefore they already had baseline neurologic disability

Figure 1 Study enrollment

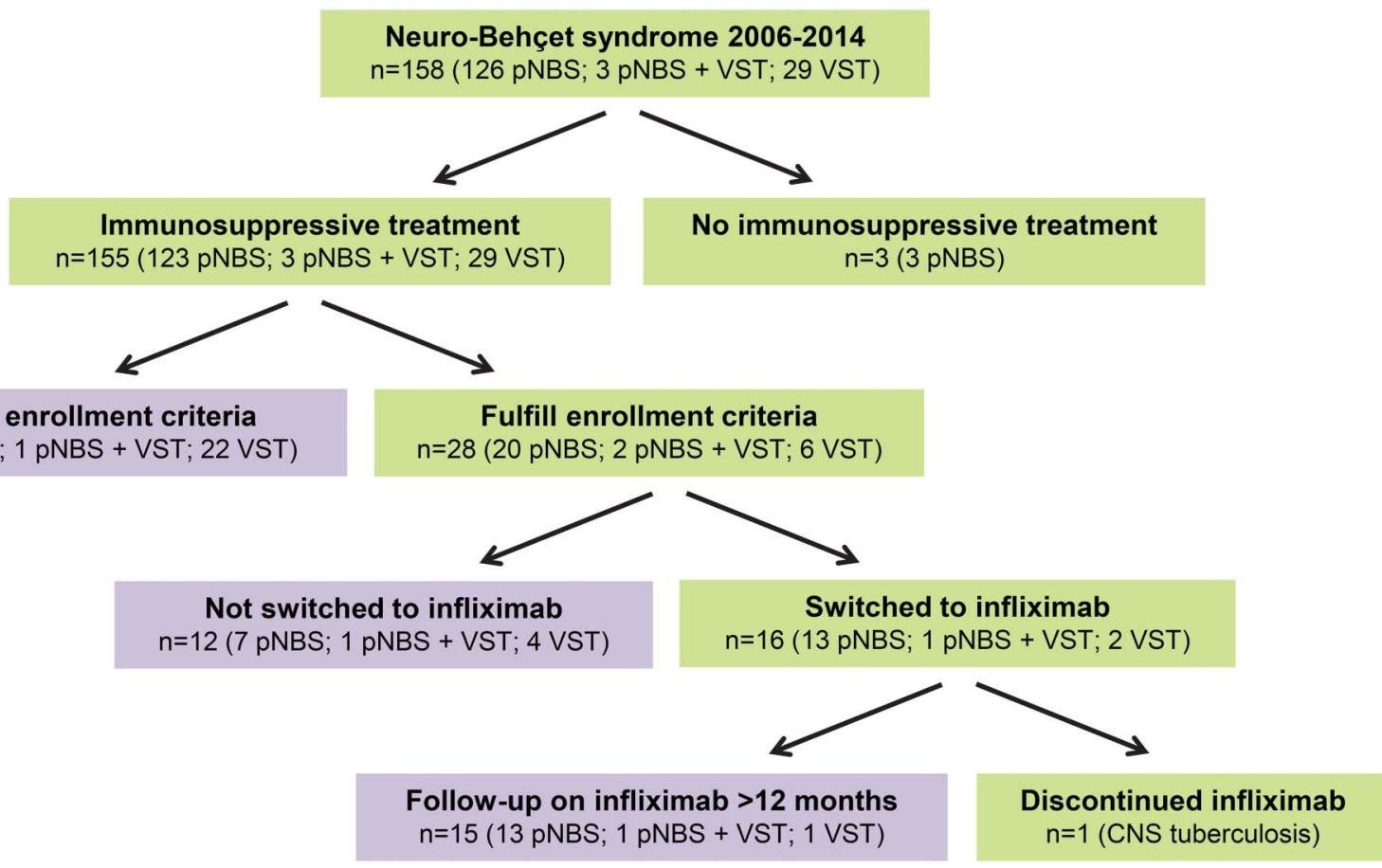

pNBS = parenchymal neuro-Behçet syndrome; VST = venous sinus thrombosis. 
Figure 2 Infliximab treatment effect

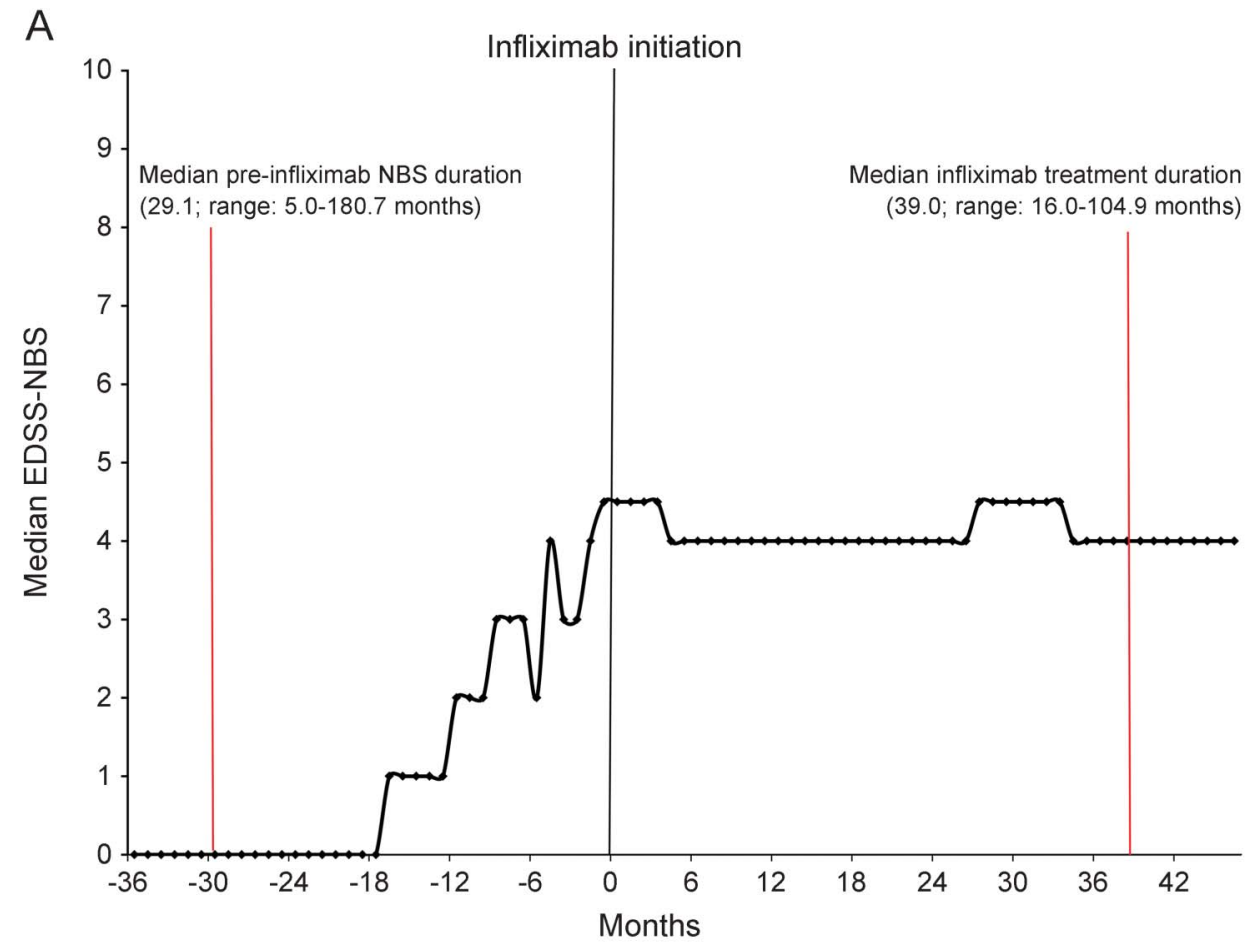

B

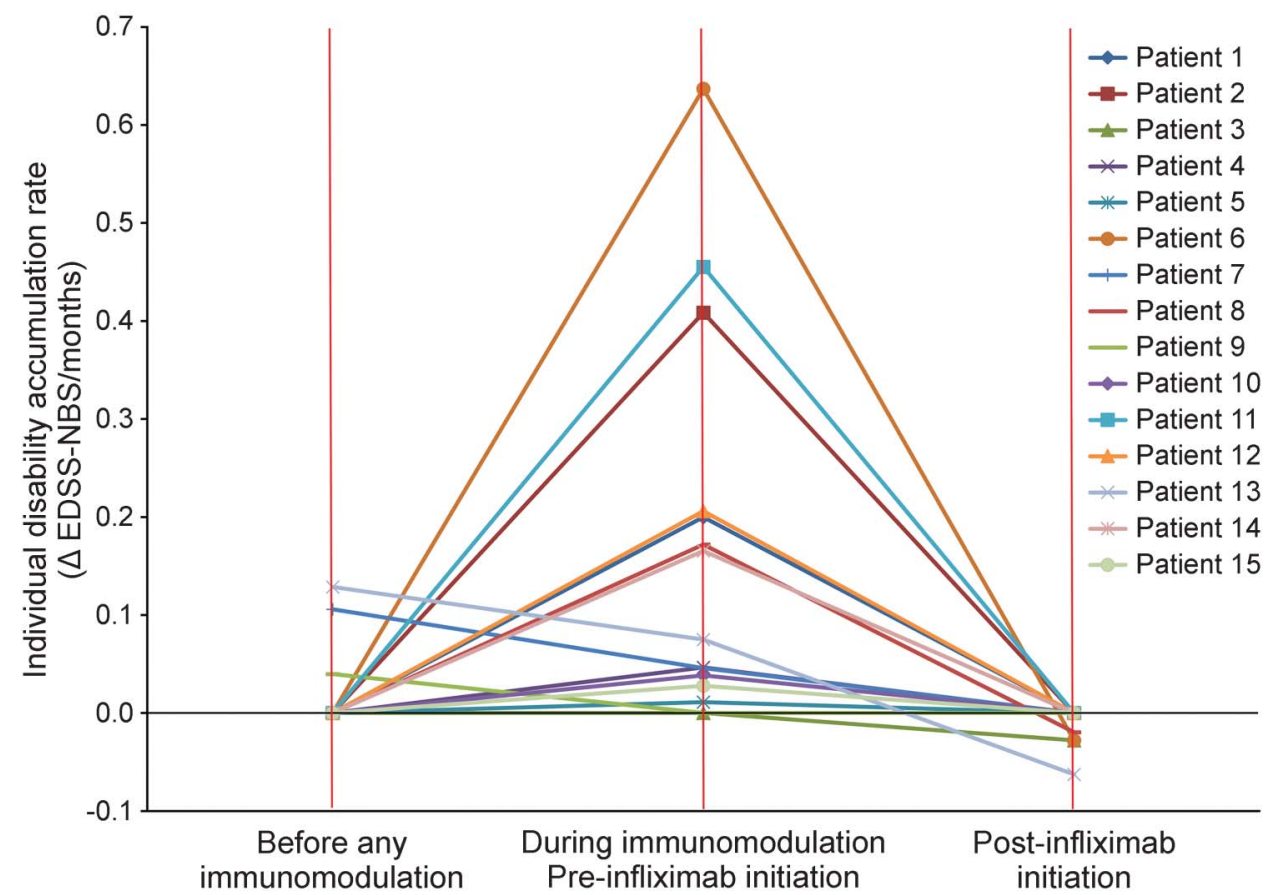

(A) Median EDSS-NBS scores of 15 patients calculated from a total of 123 clinical assessments are shown. Period corresponding to the time between median preinfliximab NBS duration (29.1 months, range 5.0-180.7 months) and the median follow-up time after infliximab initiation (39.0 months, range 16.0-104.9 months) are marked. The median EDSS-NBS scores start and continue to increase during the median preinfliximab NBS period, but clearly stabilize after the switch to infliximab. (B) Preimmunosuppression, postimmunosuppression preinfliximab, and postinfliximab disability accumulation rates for individual patients are shown. A positive disability accumulation rate indicates worsening disability. A zero value in disability accumulation rate indicates complete cessation of disability accumulation. A negative disability accumulation rate indicates improvement from enrollment disability level. EDSS-NBS = Expanded Disability Status Scale modified for neuroBehçet syndrome. 


\begin{tabular}{|c|c|c|c|}
\hline & \multirow[b]{2}{*}{$\begin{array}{l}\text { NBS that does not fulfill } \\
\text { enrollment criteria }\end{array}$} & \multicolumn{2}{|c|}{ NBS that fulfills enrollment criteria } \\
\hline & & INFX (-) & INFX (+) \\
\hline No. of patients & 127 & 12 & $15^{\mathrm{a}}$ \\
\hline Age at BD, y, median (range) & $26.6(9.0-54)$ & $24.8(20.0-36.7)$ & $28.0(6-48.4)$ \\
\hline Age at NBS, $y$, median (range) & $31.0(9.1-74)$ & $30.3(25.0-41.6)$ & $35.1(16-59.5)$ \\
\hline \multicolumn{4}{|l|}{ Clinical-radiologic syndrome at NBS onset, ${ }^{b} \mathrm{n}(\%)$} \\
\hline VST & $23(18.1)$ & $5(41.7)$ & 2 (13.3) \\
\hline Telencephalic pNBS & $17(13.4)$ & $3(25.0)$ & 2 (13.3) \\
\hline Diencephalic pNBS & $19(15.0)$ & $3(25.0)$ & 5 (33.3) \\
\hline Pre-INFX NBS duration, mo, median (range $)^{c}$ & $13.0(1.0-276.0)$ & $38.7(12.3-292.1)$ & $29.1(5-180.7)$ \\
\hline \multicolumn{4}{|l|}{ Other immunosuppressant treatments, ${ }^{\mathrm{d}} \mathrm{n}(\%)$} \\
\hline Corticosteroids & $84(66.1)$ & 10 (83.3) & $12(80.0)$ \\
\hline Azathioprine & 79 (62.2) & $9(75.0)$ & $13(86.7)$ \\
\hline Colchicine & 47 (37.0) & 5 (41.7) & $3(20.0)$ \\
\hline Cyclosporine & 20 (15.7) & $1(8.3)$ & $1(6.7)$ \\
\hline Cyclophosphamide & $10(7.9)$ & 4 (33.3) & 8 (53.3) \\
\hline Interferon $\alpha$ & $9(7.1)$ & $1(8.3)$ & $1(6.7)$ \\
\hline
\end{tabular}

Abbreviations: BD = Behçet disease; EDSS-NBS = Extended disability status scale for NBS; INFX $(+)=$ infliximab started; INFX $(-)=$ infliximab not started; NBS = neuro-Behçet syndrome; pNBS = parenchymal neuro-Behçet syndrome; VST = venous sinus thrombosis.

${ }^{a}$ Of the 16 patients who were originally started on infliximab, infliximab was discontinued at month 2 because of evidence of active pulmonary and CNS tuberculosis in one patient. This patient was excluded from the final analyses because of short duration of treatment.

${ }^{b}$ Patients may have multiple syndromes at onset.

${ }^{\mathrm{c}}$ For the patients switched to infliximab, pre-INFX last EDSS-NBS data reflect the last EDSS-NBS at the time of the switch and pre-INFX NBS duration data reflect the NBS duration from NBS onset to the time of infliximab switch. For the patients who were not switched to infliximab, pre-INFX last EDSSNBS data reflect the EDSS-NBS at the last follow-up and pre-INFX NBS duration data reflect the NBS duration from NBS onset to the last follow-up.

${ }^{d}$ Immunosuppressive medication use is organized from the highest to lowest rate in patients that were doing well, therefore did not fulfill the enrollment criteria. It is noted that preinfliximab cyclophosphamide use (reserved generally for more severe patients) is expectedly overrepresented in the patients who went onto infliximab treatment. Patients could have been on more than one immunosuppressant at a given time.

before initiation of long-term immunosuppressive treatments (EDSS-NBS scores: 2.0, 3.5, and 4.5). All the remaining 12 patients were already on immunosuppressive treatments for other symptoms of BD at the time of NBS onset. Preinfliximab cyclophosphamide use was overrepresented in the patients who fulfilled the enrollment criteria as well as those who were ultimately included in the study (table 2).

Three patients had 3 relapses while 12 had 2 relapses before the initiation of infliximab. During preinfliximab immunosuppressive use (median 20.0 months, range 3.0-180.7 months), patients accumulated disability because of partially recovering relapses reaching a median EDSS-NBS score of 5.0 (range 2.0-7.0) (figure 2).
Postinfliximab disease course. Mean age at the initiation of infliximab was $38.5 \pm 10.0$ years. Five of 15 patients were treated with infliximab alone after the switch. In the other 10 patients, infliximab was added to other medications: azathioprine $(\mathrm{n}=3)$, prednisolone $(\mathrm{n}=1)$, azathioprine + prednisolone $(n=5)$, and colchicine + prednisolone $(n=1)$. During infliximab treatment (median duration 39.0 months, range 16.0-104.9 months), all 15 patients reached the preset primary outcome measure of having no further relapses of NBS.

All patients also reached the secondary outcome measure of stability $(\mathrm{n}=11)$ or actual improvement $(\mathrm{n}=4)$ in EDSS-NBS (median score 4.0, range 2.07.0). As a group, the median EDSS-NBS score that 
was rapidly climbing before the infliximab initiation stabilized and remained so during the infliximab treatment (figure 2A). While 12 of 15 patients had stepwise disability accumulation (positive disability accumulation rate), 3 of 15 patients had improving disability (negative disability accumulation rate) while on other immunosuppressive medications before the initiation of infliximab (figure 2B). These 3 patients were included in the study because they had recurrent NBS attacks despite being on other immunosuppressive medications, therefore fulfilling the enrollment criteria for the study. All 3 continued to have disability improvement during infliximab treatment.

Patients in whom infliximab was chosen as a single agent, EDSS-NBS scores at enrollment (median score 4.5, range 2.0-7.0) were comparable to those in whom infliximab was used as an adjunct to other treatments (median score 5.0, range 3.0-7.0). At the end of study period, both groups had the same half-point drop in median EDSS-NBS scores.

All patients had new lesions associated with the index relapse leading to the decision to switch to infliximab. Of the total of 27 brain MRIs performed in 15 patients after NBS onset but before the initiation of infliximab, 7 (26\%) had gadolinium-enhancing lesions while of the 18 brain MRIs performed after the initiation of infliximab, none had enhancing lesions. Figure 3 depicts the treatment duration and radiologic response of infliximab in 2 example patients.

While we did not primarily target systemic manifestations of $\mathrm{BD}$, of the 15 patients who completed treatment, one patient had a documented episode of folliculitis and another patient had an episode of oral aphthous during the period of postinfliximab observation.

Once the patient who developed early complications with tuberculosis was excluded from the study, none of the remaining 15 patients showed any major adverse events during the infliximab treatment. However, in a patient who was catheter-dependent, recurrent urinary tract infections led to discontinuation of infliximab after 47 months of treatment. The patient was still included in the final analyses given the sufficient treatment interval.

None of the common side effects such as rash $(\mathrm{n}=1)$, headaches $(\mathrm{n}=2)$, and nausea $(\mathrm{n}=2)$ were deemed bad enough to discontinue treatment. Expectedly, in case of any new-onset headache or nausea

Figure $3 \quad$ Improvement and stability of MRI in 2 example patients

36-year-old male patient

Pre-infliximab
EDSS 4.0

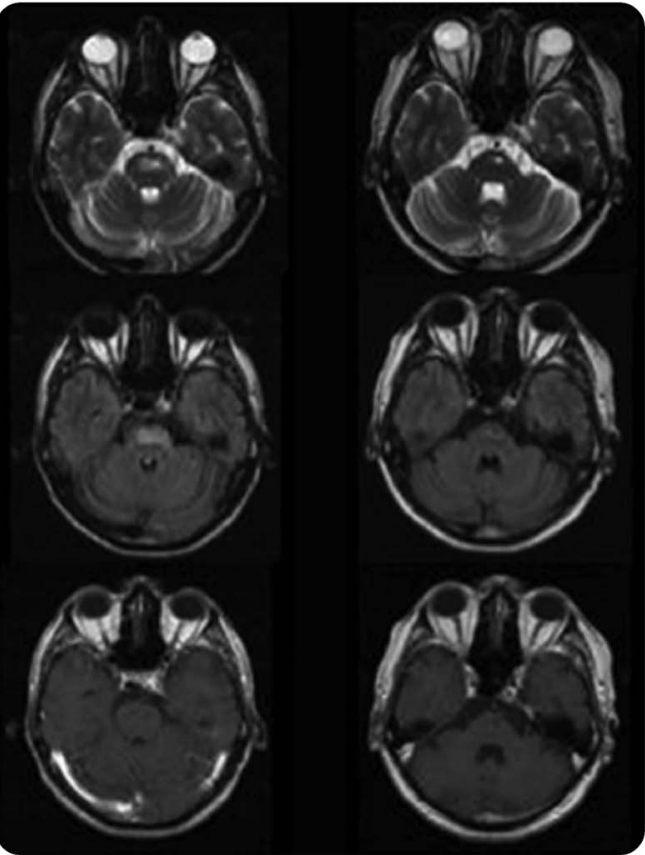

T2W and FLAIR

hyperintense gandolinium enhancing lesion on the left side of pons
Post-infliximab EDSS 2.0

62 months after first dose

Partially regressed lesion without gadolinium enhancement 35-year-old female patient

$\begin{array}{cc}\text { EDSS } 5.0 \text { before } & \text { Post-infliximab } \\ 10 \text { days of IVMP } & \text { EDSS } 4.0 \\ \text { and first dose } \\ \text { of infliximab } & 26 \text { months after } \\ \text { first dose }\end{array}$

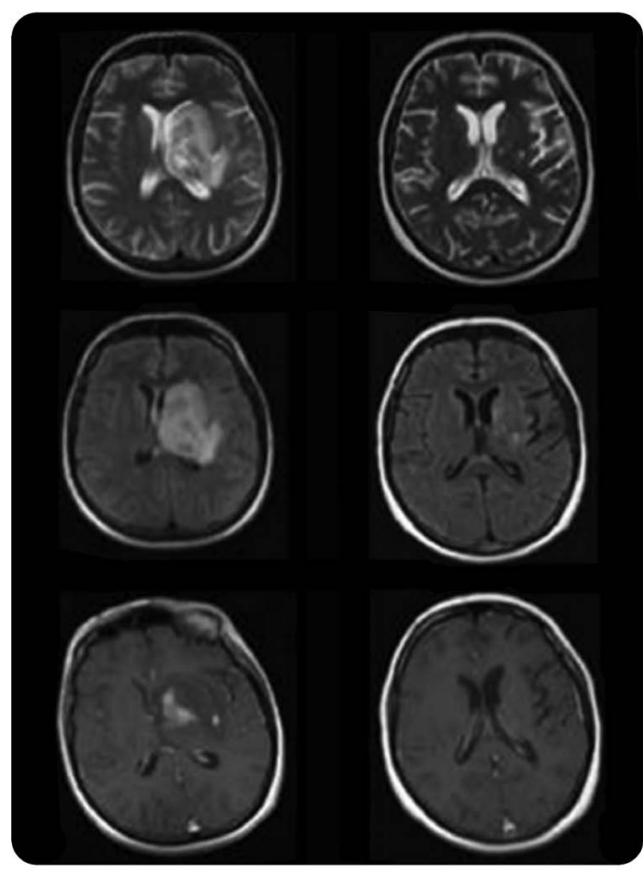

Tumefactive gadolinium enhancing thalamic lesion with peripheral edema and mass effect
Markedly regressed lesion without gadolinium enhancement

EDSS $=$ Expanded Disability Status Scale; FLAIR = fluid-attenuated inversion recovery; IVMP = IV methylprednisolone. 
presentation, patients were evaluated both clinically and with imaging to rule out NBS rather than infliximab leading to the symptoms. There were no patients with a recurrent NBS relapse associated with headache during the study period.

DISCUSSION Here, we show that in patients with NBS who had ongoing clinical relapses on single or multiple immunosuppressants, a switch to infliximab completely stopped clinical disease activity. Outside of gastrointestinal involvement, TNF blockade was first reported in systemic BD in 2001 and in NBS in 2003. ${ }^{29,30}$ Ours is a large published case series in one center to add to the promising findings from previously published case reports that infliximab is a viable intervention for NBS. ${ }^{8-26}$

In this real-world experience, the patients switched to infliximab had a higher baseline median EDSSNBS score than those that were not switched to infliximab. Also, the preinfliximab cyclophosphamide use was overrepresented in the patients who were switched to infliximab. Since cyclophosphamide is reserved generally for more aggressive immunotherapy, both as a single agent or as an add-on, this is further evidence that treatment escalation was already happening before the switch. At the group level, the median EDSS-NBS scores as depicted in figure 2A clearly show stabilization of disability accumulation after switching to infliximab. In addition, at an individual level, some patients had improvement in EDSS-NBS scores, most remained the same, and none worsened under infliximab. While disability assessment was our secondary endpoint, since there were no patients in the study with a purely progressive disease course that could also be seen in NBS, ${ }^{3}$ it is not surprising that by the elimination of relapses during the study period, disability accumulation stabilized.

Patients who did not fulfill the enrollment criteria had a shorter NBS duration than those who did fulfill the criteria before they began infliximab. We had originally shown that as the duration of follow-up increased beyond 1 year after NBS onset, the risk of recurrent relapses and progression increased by about 6 -fold, and beyond 3 years, the risk of recurrent relapses and progression increased by about 2 -fold. ${ }^{3}$ Therefore, it is likely that given enough time, more patients in our study could have failed other immunosuppressive medications. Patients enrolled in our study already had their second relapse on average about 29 months after NBS onset and we were able to demonstrate sustained robust efficacy of infliximab for the 39-month median follow-up time posttreatment switch. Our study suggests that in a prospective randomized trial of infliximab, a follow-up time of 3 years is likely long enough to show a difference.

Within the same study period (2006-2014), 74 patients with BD without NBS (25 with systemic arterial involvement, 49 with eye involvement) in the same center were started on infliximab because of failure of other immunosuppressants. At the time of last follow-up, none of these patients had developed NBS. When compared to the expected prevalence of $5 \%$ NBS within the larger BD population, ${ }^{3}$ this observation suggests that early use of infliximab can even be beneficial in prevention of NBS.

To check whether our enrollment was representative of the larger NBS population, we compared demographics among 3 groups: (1) patients who did not fulfill the study criteria, (2) patients who fulfilled the study criteria but were not offered infliximab for reasons mentioned in the methods section and, (3) patients who fulfilled the criteria and were enrolled in our trial. Lack of difference between demographics of each group suggested no systematic bias in recruitment. NBS duration was shorter for those who did not fulfill the enrollment criteria, but that would be expected as one of our requirements was to have more than one relapse and the risk of recurrent relapses increases with time as discussed previously. Most of our patients on infliximab had spinal cord or brainstem-cerebellar syndromes at onset, unfavorable prognostic factors, suggesting that overall patients included in our study would be more likely to relapse or progress. ${ }^{3}$ They neither had further relapses nor progressed during the study period.

The choice of single agent vs adjunct use of infliximab was based on the treating physician's clinical judgement at the time. Two-thirds of our patients were therefore on combination therapy. During the tenure of our study, combination with immunosuppressant therapy was suggested to be associated with better outcome in a limited report of 2 patients. ${ }^{16}$ Patients in whom infliximab was chosen as a single agent in our study had baseline EDSS-NBS scores lower than patients in whom infliximab was used as an adjunct to other treatments. This further supports the notion that infliximab can be used as a single agent as well as an adjunct arm in a future prospective trial.

In the patient diagnosed with tuberculosis, screening was negative before infliximab initiation and was previously treated with cyclophosphamide, azathioprine, and steroids. Since he became positive shortly after infliximab initiation, active tuberculosis likely evolved right at the time of treatment initiation. While difficult to assign causality, this case further emphasizes the need for screening with quantiFERON testing when using TNF- $\alpha$ blockers.

Although we did not observe any other major side effects under infliximab in our case series of 15 patients, this also has to be interpreted with caution. While we observed some common side effects such as rash, headaches, and nausea, the number of individuals in our study is too small to see a strong presence of 
some of these adverse events, which are certainly observed in the longer-followed and larger BD population treated with infliximab.

Infliximab is a viable alternative in preventing further relapses and stabilizing disability in patients with NBS whose other immunosuppressive treatments failed with relative safety. However, we need a randomized trial of infliximab vs other immunosuppressant agents after the first neurologic episode, preferably with a combination arm, before confidently recommending infliximab as a first-line agent in NBS.

\section{AUTHOR CONTRIBUTIONS}

Drs. Siva, Kantarci, and Zeydan contributed equally to the manuscript. Drs. Zeydan, Uygunoglu, and Siva had access to all of the clinical information from patients. Study concept and design: Drs. Siva and Kantarci contributed equally. Acquisition of data: Drs. Saip, Uygunoglu, Zeydan, Demirci, Seyahi, Ugurlu, Hamuryudan, Siva. Analysis and interpretation of data: Drs. Zeydan, Kantarci, Siva. Drafting of the manuscript: Drs. Kantarci, Zeydan, Demirci. Critical Revision of the manuscript for important intellectual content: Drs. Kantarci, Zeydan, Siva. Statistical analysis: Drs. Kantarci, Zeydan. Study Supervision: Drs. Siva, Hamuryudan, Kantarci.

\section{ACKNOWLEDGMENT}

Dr. Zeydan's fellowship position in the Department of Neurology, Mayo Clinic, Rochester, MN, is partially supported by an unrestricted grant from the Turkish Neurological Society.

\section{STUDY FUNDING}

Dr. Zeydan's fellowship position in the Department of Neurology, Mayo Clinic, Rochester, MN, is partially supported by an unrestricted grant from the Turkish Neurological Society.

\section{DISCLOSURE}

B. Zeydan received research support from the Turkish Neurologic Society. U. Uygunoglu is on the editorial board for the Turkish Journal of Neurology, received research support from The Scientific and Technological Research Council of Turkey. S. Saip, O.N. Demirci, E. Seyahi, and S. Ugurlu report no disclosures. V. Hamuryudan received speaker honoraria from BMS, MSD, Pfizer, AbbVie, Amgen, UCB, is associate editor for Letter to Editor Rheumatology. A. Siva received travel funding from Merck Serono, Biogen Idec/Gen Pharma of Turkey, Novartis, Teva, is on the editorial board for Journal of Neurologic Sciences, Journal of Headache and Pain, Turkish Neurologic Journal, Turkish Pain Journal, Brazilian Journal of Multiple Sclerosis, receives consulting fees from Biogen Idec, Novartis, Teva, Genzyme, Roche, gives educational presentations at programs and symposia prepared by EXCEMED, received research grants from The Scientific and Technological Research Council of Turkey. O.H. Kantarci's institution received speaker honoraria from Novartis Pharmaceutical, Biogen, he performed a grant review for the National Multiple Sclerosis Society, received research support from the European Regional Development Fund, National Multiple Sclerosis Society, Mayo Foundation, Hilton Foundation, his spouse serves on the data safety monitoring board of Takeda Global Research and Development Center, INC, on the data monitoring board for Pfizer Inc., Janssen Alzheimer Immunotherapy, is funding by NIH and Minnesota Partnership for Biotechnology and Medical Genomics. Go to Neurology.org/nn for full disclosure forms.

Received April 7, 2016. Accepted in final form May 18, 2016.

\section{REFERENCES}

1. Behçet H. Uber Residivierende, Aphtöse, durch ein Virus verursachte Geschwüre am Mund, am Auge und an den Genitalien. Derm Woschenscr 1937;105:1152-1157.
2. Criteria for diagnosis of Behçet's disease. International Study Group for Behçet's Disease. Lancet 1990;335:1078-1080.

3. Siva A, Kantarci OH, Saip S, et al. Behcet's disease: diagnostic and prognostic aspects of neurological involvement. J Neurol 2001;248:95-103.

4. Akman-Demir G, Saip S, Siva A. Behcet's disease. Curr Treat Options Neurol 2011;13:290-310.

5. Kalra S, Silman A, Akman-Demir G, et al. Diagnosis and management of neuro-Behcet's disease: international consensus recommendations. J Neurol 2014;261:1662-1676.

6. Hatemi G, Silman A, Bang D, et al. Management of Behçet disease: a systematic literature review for the European League against Rheumatism evidence-based recommendations for the management of Behçet disease. Ann Rheum Dis 2009;68:1528-1534.

7. Hatemi G, Silman A, Bang D, et al. EULAR recommendations for the management of Behçet disease. Ann Rheum Dis 2008;67:1656-1662.

8. Uygunoğlu U, Pasha M, Saip S, Siva A. Recurrent longitudinal extensive transverse myelitis in a neuro-Behçet syndrome treated with infliximab. J Spinal Cord Med 2015; 38:111-114.

9. Di Filippo M, Di Gregorio M, Nannini C, et al. Infliximab monotherapy for neuro-Behçet's disease: a case report. J Neurol Sci 2014;347:389-390.

10. Kanemaru H, Makino T, Jinnin M, Yonemitsu A, Makino K, Ihn H. Case of neuro-Behçet's disease successfully maintained a remission using infliximab for 2 years. J Dermatol 2013;40:632-634.

11. Kuroda R, Suzuki J, Muramatsu M, et al. Efficacy of infliximab in neuro-Behçet's disease presenting with isolated longitudinally extensive transverse myelitis. J Neurol 2013;260:3167-3170.

12. Coulter I, Huda S, Baborie A, Jacob A. Longitudinally extensive transverse myelitis as the sole presentation of neuro-Behçet's disease responding to infliximab. J Spinal Cord Med 2012;35:122-124.

13. Urbaniak P, Hasler P, Kretzschmar S. Refractory neuroBehçet treated by tocilizumab: a case report. Clin Exp Rheumatol 2012;30:S73-S75.

14. Fasano A, D'Agostino M, Caldarola G, Feliciani C, De Simone C. Infliximab monotherapy in neuro-Behçet's disease: four year follow-up in a long-standing case resistant to conventional therapies. J Neuroimmunol 2011; 28:105-107.

15. Kadowaki S, Matsuda N, Moriya A, et al. Infliximab treatment trial in a patient with neuro-Behçet's disease unresponsive to other treatments [in Japanese]. Rinsho Shinkeigaku 2011;51:261-266.

16. Borhani Haghighi A, Safari A, Nazarinia MA, Habibagahi Z, Shenavandeh S. Infliximab for patients with neuro-Behcet's disease: case series and literature review. Clin Rheumatol 2011;30:1007-1012.

17. Matsui $T$, Ishida $T$, Tono $T$, Yoshida $T$, Sato $S$, Hirohata S. An attack of acute neuro-Behçet's disease during the course of chronic progressive neuro-Behçet's disease: report of two cases. Mod Rheumatol 2010;20: 621-626.

18. Leccese P, D'Angelo S, Angela P, Coniglio G, Olivieri I. Switching to adalimumab is effective in a case of neuroBehcet's disease refractory to infliximab. Clin Exp Rheumatol 2010;28:S102.

19. Abalos-Medina GM, Sanchez-Cano D, Ruiz-Villaverde G, Ruiz-Villaverde R, Quirosa Flores S, Raya Alvarez E. 
Successful use of infliximab in a patient with neuro-Behçet's disease. Int J Rheum Dis 2009;12:264-266.

20. Pipitone N, Olivieri I, Padula A, et al. Infliximab for the treatment of neuro-Behçet's disease: a case series and review of the literature. Arthritis Rheum 2008;59:285-290.

21. Kikuchi H, Aramaki K, Hirohata S. Effect of infliximab in progressive neuro-Behçet's syndrome. J Neurol Sci 2008; 272:99-105.

22. Borhani Haghighi A, Safari A. Anti-tumor necrotic factor antibody for treatment of neuro-Behçet's disease, a case report. Clin Neurol Neurosurg 2008;110:315-316.

23. Fujikawa K, Aratake K, Kawakami A, et al. Successful treatment of refractory neuro-Behçet's disease with infliximab: a case report to show its efficacy by magnetic resonance imaging, transcranial magnetic stimulation and cytokine profile. Ann Rheum Dis 2007;66:136-137.

24. Alty JE, Monaghan TM, Bamford JM. A patient with neuro-Behçet's disease is successfully treated with etanercept: further evidence for the value of TNFalpha blockade. Clin Neurol Neurosurg 2007;109:279-281.

25. Ribi C, Sztajzel R, Delavelle J, Chizzolini C. Efficacy of TNF \{alpha\} blockade in cyclophosphamide resistant
neuro-Behcet disease. J Neurol Neurosurg Psychiatry 2005;76:1733-1735.

26. Sarwar H, McGrath H Jr, Espinoza LR. Successful treatment of long-standing neuro-Behçet's disease with infliximab. J Rheumatol 2005;32:181-183.

27. Hanauer SB, Feagan BG, Lichtenstein GR, et al. Maintenance infliximab for Crohn's disease: the ACCENT I randomised trial. Lancet 2002;359:1541-1549.

28. Rutgeerts P, Sandborn WJ, Feagan BG, et al. Infliximab for induction and maintenance therapy for ulcerative colitis. N Engl J Med 2005;353:2462-2476.

29. Robertson LP, Hickling P. Treatment of recalcitrant orogenital ulceration of Behçet's syndrome with infliximab. Rheumatology 2001;40:473-474.

30. Licata G, Pinto A, Tuttolomondo A, et al. Antitumour necrosis factor alpha monoclonal antibody therapy for recalcitrant cerebral vasculitis in a patient with Behçet's syndrome. Ann Rheum Dis 2003;62: 280-281.

31. Kurtzke JF. Rating neurologic impairment in multiple sclerosis: an Expanded Disability Status Scale (EDSS). Neurology 1983;33:1444-1452. 


\title{
Neurology \\ Neuroimmunology \& Neuroinflammation
}

\author{
Infliximab is a plausible alternative for neurologic complications of Behçet disease \\ Burcu Zeydan, Ugur Uygunoglu, Sabahattin Saip, et al. \\ Neurol Neuroimmunol Neuroinflamm 2016;3; \\ DOI 10.1212/NXI.0000000000000258
}

This information is current as of July 8, 2016

\section{Updated Information \& Services}

\section{References}

Citations

Subspecialty Collections

Permissions \& Licensing

Reprints including high resolution figures, can be found at: http://nn.neurology.org/content/3/5/e258.full.html

This article cites 31 articles, 6 of which you can access for free at: http://nn.neurology.org/content/3/5/e258.full.html\#\#ref-list-1

This article has been cited by 1 HighWire-hosted articles: http://nn.neurology.org/content/3/5/e258.full.html\#\#otherarticles

This article, along with others on similar topics, appears in the following collection(s):

All Immunology

http://nn.neurology.org//cgi/collection/all_immunology

Cerebral venous thrombosis

http://nn.neurology.org//cgi/collection/cerebral_venous_thrombosis Clinical trials Observational study (Cohort, Case control) http://nn.neurology.org//cgi/collection/clinical_trials_observational_stu dy_cohort_case_control

Information about reproducing this article in parts (figures,tables) or in its entirety can be found online at:

http://nn.neurology.org/misc/about.xhtml\#permissions

Information about ordering reprints can be found online: http://nn.neurology.org/misc/addir.xhtml\#reprintsus

Neurol Neuroimmunol Neuroinflamm is an official journal of the American Academy of Neurology.

Published since April 2014, it is an open-access, online-only, continuous publication journal. Copyright $\odot$ 2016 American Academy of Neurology. All rights reserved. Online ISSN: 2332-7812.

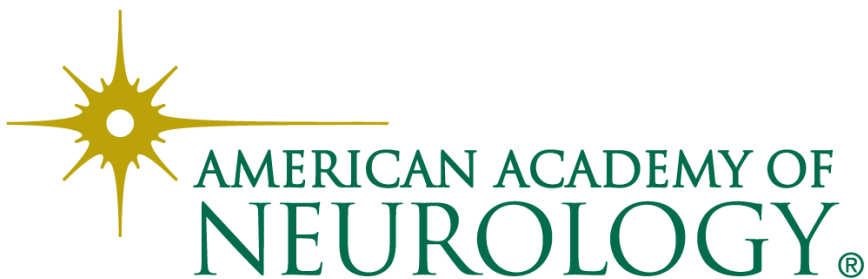

